
Operated with DW $\|$ Operated with AC \| $\begin{gathered}\text { Not pre-acclimated, } \\ \text { started on FE with }\end{gathered}$ and switched to FE and switched to FE DW inoculum

Pre-acclimation

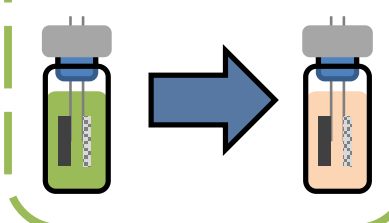

C-WW

Anodes enriched in MFCs fed DW and transferred to MECs
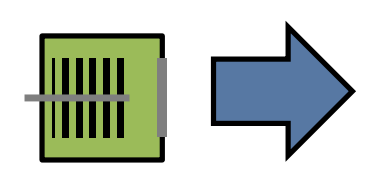

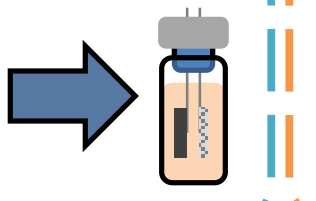

C-FE

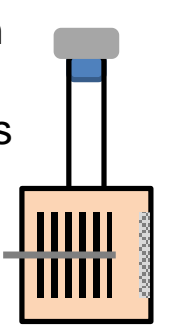

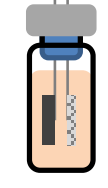

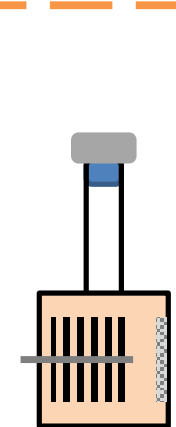

0

Not preacclimated, started in MECs with DW as an inoculum improved COD removal

No influence on current
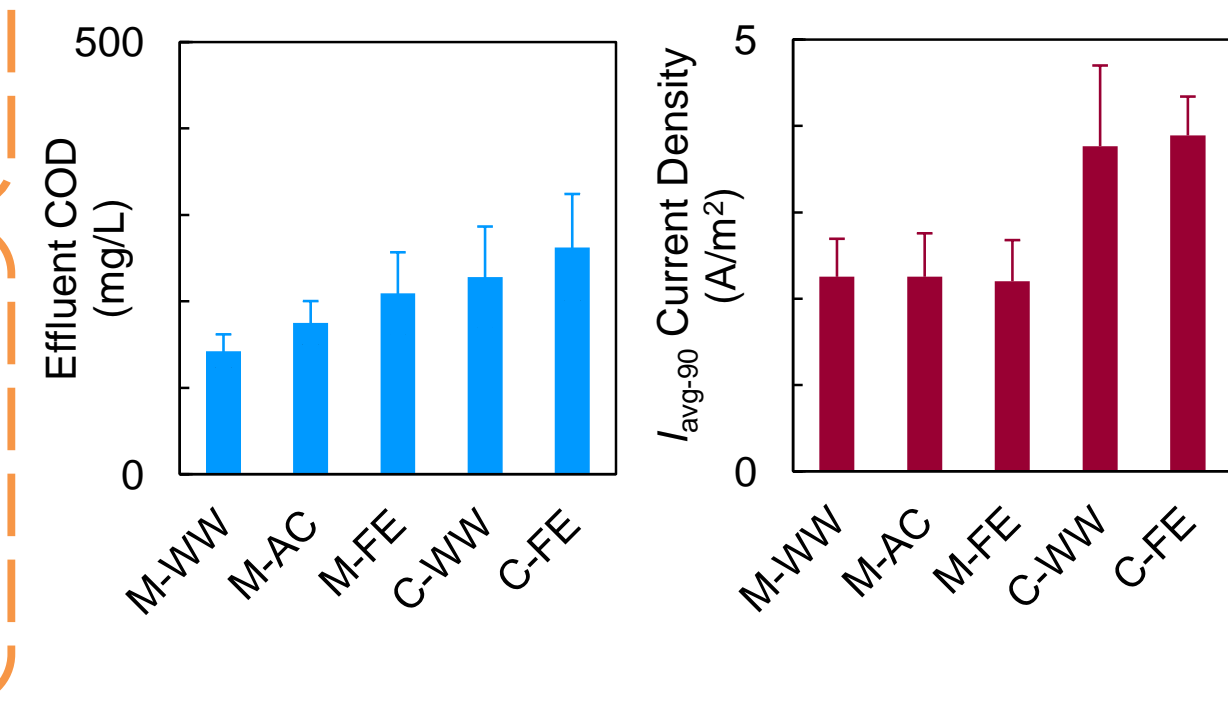
1 Date: $\quad$ March 15, 2015

2 Submitted to: International Journal of Hydrogen Energy

\section{Anode Acclimation Methods and Their Impact on Microbial Electrolysis Cells Treating} Fermentation Effluent

\author{
Mark L. Ullery and Bruce E. Logan*
}

\author{
Department of Civil and Environmental Engineering, 212 Sackett Building, The Pennsylvania \\ State University, University Park, PA 16802, USA \\ *Corresponding Author: E-mail: blogan@psu.edu, Tel: +1 8148637908
}

ABSTRACT

There is a lack of standardized acclimation procedures for evaluating treatability of different wastewaters, and such tests are often conducted using different types of microbial electrolysis cells (MECs). Two different types of MECs (mini or cube) were therefore acclimated using two different substrates (acetate or domestic wastewater) to see the impact of these procedures on the resulting treatment efficiency using the same cellulose fermentation effluent. COD removal was slightly larger using mini MECs (81-86\%) than cube MECs (79-82\%). Pre-acclimation of mini MECs to domestic wastewater increased COD removal slightly compared to non-acclimated tests with fermentation effluent, but acclimation differences for the cube MECs were not statistically significant. Gas production was not significantly different for cube pre-acclimated MECs compared to those acclimated only to the fermentation effluent. Current densities were higher for the cube reactors than the mini MECs, but they were unaffected by acclimation procedure (pre-acclimation or direct use of fermentation effluent). These results show that mini MECs acclimated to a readily available complex source of organic matter (domestic wastewater) can produce equivalent or slightly superior results for tests with a different complex wastewater (fermentation effluent), and that mini MEC performance is comparable to that of cube MECs. 
28 The similarity of reactor performance allows the use of simple and inexpensive mini MECs that

29 can be acclimated to domestic wastewater and subsequently used to test different types of

30 industrial effluents.

32 KEYWORDS: Microbial Electrolysis Cells; Fermentation Effluent; Mini Microbial Electrolysis

33 Cells; Acclimation

\section{1. Introduction}

35 Advances in anaerobic biological treatment technology have redefined what can be considered

36 "waste" by demonstrating that useful products can be generated or recovered from a wide range

37 of domestic, industrial and agricultural byproducts [1,2]. Electricity, hydrogen, methane and

38 various chemicals can be generated through these processes, but hydrogen is especially attractive

39 because it is a valuable product that has a high energy density and it has broad use in different

40 industrial applications [3-5]. Waste products, such as crop biomass, food waste, and industrial

41 wastewaters rich in carbohydrates can be used as renewable energy sources to produce hydrogen

42 gas by dark fermentation [6-11]. However, while one mole of glucose can stoichiometrically be

43 converted to 12 moles of hydrogen, maximum yields of only 2-3 $\mathrm{mol} \mathrm{H}_{2} / \mathrm{mol}$ glucose are

44 typically observed because other end products, like acetate and butyrate, are also produced along

45 with hydrogen $[1,7,9,12]$. The effluent from a dark fermentation process is therefore rich in

46 organic acids, ethanol, and other organics that cannot be further fermented to produce hydrogen,

47 which limits conversion efficiencies and energy recovery $[8,11,13]$.

48 To improve overall yields of substrate conversion to hydrogen gas, dark fermentation

49 processes can be integrated with post treatment systems such as microbial electrolysis cells

50 (MECs) [12]. MECs utilize exoelectrogenic microbes that can readily convert organic acids, such 
51 as acetate, into electrical current, making them useful for treating fermentation effluent and

52 recovering additional energy [14-17]. Exoelectrogenic microbes form a biofilm on a conductive

53 anode, which is coupled with a hydrogen-evolving cathode to complete the cell. MECs require a

54 source of electrical power to drive the hydrogen evolution reaction at the cathode, with $0.5-1.0 \mathrm{~V}$

55 of additional potential typically applied to supplement the potential generated by the anode [18-

56 21]. This power can be generated by renewable sources, such as solar and wind, or from salinity

57 gradient energy derived from natural or artificial solutions [22, 23].

58 A combined treatment process using a small (cube type) MEC with a dark fermentation

59 effluent was shown to increase hydrogen yields to nearly $10 \mathrm{~mol} \mathrm{H}_{2} / \mathrm{mol}$ glucose from a

60 cellobiose feedstock, compared to $1.65 \mathrm{~mol} \mathrm{H}_{2} / \mathrm{mol}$ glucose by dark fermentation alone [24].

61 However, this comparison was made on the basis of only volatile fatty acids and alcohols.

62 Fermentation of cellulosic substrates can also result in a high concentrations of protein in the

63 effluent due to the production of celluosomes, for example by Clostridium thermocellum, that are

64 needed to break down the cellulose into sugars [37, 38]. Proteins can be degraded in MECs, but

65 they have been infrequently studied in these systems [36, 38]. Since proteins can be used as a

66 substrate in MECs, their concentrations will also be important when examining reactor

67 performance on the basis of COD removal.

68 MECs used in tests with complex wastewaters have been acclimated using different

69 approaches, but the impact of these different methods has not been well studied for complex

70 wastewaters such as fermentation effluents. When a single substrate such as acetate is used in an

71 MEC, it has been shown that using effluent from a reactor pre-acclimated to that substrate

72 improves performance $[39,40]$. However, in some studies with complex wastewaters, for

73 example, fermentation effluent of glycerol and molasses wastewaters, the reactors were 
74 acclimated using only acetate prior to tests on these wastewaters that contained a rich mixture of

75 alcohols and volatile fatty acids $[10,25]$. The impact of pre-acclimation to the fermentation

76 effluent or another complex wastewater was not examined. It has been shown by others that pre-

77 acclimation of MECs to a complex source of organic matter and high concentrations of bacteria

78 (domestic wastewater) improves performance of MECs treating an industrial wastewater

79 compared to reactors acclimated only to the industrial wastewater [41, 42]. The microbial

80 diversity of anode communities is known to increase for complex organic matter sources

81 compared to single substrates. Exoelectrogenic microbes that produce electricity in MECs can

82 only use a relatively limited number of different substrates [43, 44], and therefore microbial

83 communities that develop in reactors fed a single substrate, such as acetate, are primarily

84 dominated by various Geobacter species [45-47]. However, communities that develop in reactors

85 fed a complex source of organic matter, such as domestic wastewater, are much more rich and

86 diverse $[14,27,28,48]$. Therefore, it is not known to what extent the pre-acclimation process

87 can affect the performance of MECs treating complex wastewaters such as fermentation

88 effluents.

89 Various types of MECs have been used to convert residual organic matter fermentation

90 effluent into hydrogen [10, 13, 24-26], but there have been no comparisons of treatability using

91 these different types of reactors. Most tests on fermentation effluents have been done using

92 small, cube-shaped reactors with 25-32 mL per single-chamber, fed-batch test [13, 24, 32-34],

93 although some have also been done using two-chamber MECs [10, 35] or continuous flow

94 conditions [36] that can use larger volumes of $350 \mathrm{~mL}$ per batch [36] or $137 \mathrm{~mL}$ for a set

95 hydraulic retention time [36] which is typically one day or less. Inexpensive ( $\$ 1-2$ each) mini

96 MEC reactors can be easily manufactured from readily available materials [49]. They also have a 
97 very small liquid volume $(5 \mathrm{~mL})$ and can be operated with a large number of reactors in parallel, 98 making them useful for studying a wide variety of conditions or substrates [41, 42]. Cube

99 reactors are relatively expensive to make ( $\$ 100$ each or more) but they use somewhat larger

100 volumes of liquid (which typically must be transported from distant sites to the laboratory). For

101 example, a two-month long test using cube reactors in duplicate (assuming new solution every

102 two days, and $32 \mathrm{~mL}$ for each reactor) would require $\sim 2$ liters of a sample, compared to less than

103 half a liter for mini-MECs run in triplicate. To reduce liquid sample collection and shipments,

104 tests with cube MECs are often made with a single reactor (sometimes duplicates) but not in

105 triplicate. Mini MECs could be used as a less expensive platform for treatability testing, and

106 reduce volumes of samples that need to be shipped, but the two types of reactors have not been

107 previously compared using an industrial wastewater or fermentation effluent.

108 The goals of this study were to examine the impact of pre-acclimation procedures (using

109 different inocula), and to compare two different reactor configurations relative to treatment

110 efficiencies using a cellulose fermentation effluent. We compared commonly used MEC pre-

111 acclimation procedures for complex effluents, based on first using acetate or domestic

112 wastewater [18, 42], with acclimation of MECs only to fermentation effluent. The two reactor

113 types examined here were inexpensive small-volume mini MECs that utilize commonly available

114 parts and materials, and more standardized cube-type reactors. Performance of these MECs was

115 evaluated in terms of COD and protein removal, along with gas recovery and coulombic

116 efficiencies. 


\section{$118 \quad 2.1 \quad$ Fermentation Effluent and Acclimation Substrates}

119 Fermentation effluent was produced in continuous cultures using Clostridium thermocellum fed 1201191 medium containing synthetic cellulose (Avicel, $5 \mathrm{~g} / \mathrm{L}$ ) at the National Renewable Energy

121 Lab in Golden, CO, USA [11]. Effluent samples were stored on ice and shipped overnight to

122 University Park, PA, USA. Raw fermentation effluent had a COD concentration of $7180 \pm 100$

$123 \mathrm{mg} / \mathrm{L}$, conductivity of $4.5 \mathrm{mS} / \mathrm{cm}$ and a $\mathrm{pH}$ of 7.1. The raw fermentation effluent was diluted in

$12450 \mathrm{mM}$ PBS to $1230 \pm 70 \mathrm{mg} / \mathrm{L}$ of COD with a pH of 7.1 and conductivity of $3.7 \mathrm{mS} / \mathrm{cm}$ before

125 use in MEC reactors. Domestic wastewater, used as inoculum and substrate for pre-acclimation,

126 was collected from the outlet of the primary clarifier at the Penn State University wastewater

127 treatment plant in University Park, PA, USA ( 460 mg/L COD, $0.9 \mathrm{mS} / \mathrm{cm})$. Fresh domestic

128 wastewater samples were collected at least every 2 weeks, and stored at $4^{\circ} \mathrm{C}$ prior to use. The

129 acetate medium used in MEC acclimation consisted of $1 \mathrm{~g} / \mathrm{L}$ of sodium acetate dissolved in 50

$130 \mathrm{mM}$ PBS (PBS; $\left.2.45 \mathrm{~g} / \mathrm{L} \mathrm{NaH}_{2} \mathrm{PO}_{4}, 4.58 \mathrm{~g} / \mathrm{L} \mathrm{Na}_{2} \mathrm{HPO}_{4}\right)$ with additional nutrients $(0.31 \mathrm{~g} / \mathrm{L}$

$131 \mathrm{NH}_{4} \mathrm{Cl}, 0.13 \mathrm{~g} / \mathrm{L} \mathrm{KCl}$, trace vitamins and minerals) added (4.0 mS/cm) [55].

\section{$132 \quad 2.2 \quad$ Reactor Construction}

133 Mini MECs were constructed as previously described [49] using $5 \mathrm{~mL}$ glass serum bottles

134 (Wheaton, Millville, NJ, USA) as the reactor body, graphite block anodes $(1.5 \times 1 \times 0.32 \mathrm{~cm}$,

135 Grade GM-10; GraphiteStore.com, Inc., Buffalo Grove, IL, USA) and stainless steel mesh

136 cathodes $(1.5 \times 1 \mathrm{~cm}$, Type 304, $50 \times 50$ mesh size; McMaster-Carr, Elmhurst, IL, USA). Anodes

137 were connected to titanium wire current collectors, while cathodes were connected to stainless

138 steel wires (0.032 gauge; Malin Co., Brookpark, OH, USA). A butyl rubber stopper and 
139 aluminum crimp cap were used to seal each reactor, with the current collecting wires extending

140 through the stopper so they could be connected to an external circuit. Mini MECs were operated

141 in triplicate.

142 Cube MEC were constructed from 4-cm polycarbonate cubes, and contained a 3-cm diameter

143 cylindrical anode chamber ( $32 \mathrm{~mL}$ liquid volume), with a 1.6-cm diameter by $7-\mathrm{cm}$ tall glass

144 tube glued to the top of the reactor to provide headspace [18]. The anodes were carbon fiber

145 brushes made using twisted titanium wire current collectors $(2.5-\mathrm{cm}$ diameter by 2.5 -cm length;

146 Panex 35 polyacrylonitrile fiber, Zoltek, St. Louis, MO, USA) that were heat treated at $450^{\circ} \mathrm{C}$ for

14730 minutes before use to remove contaminants and create more favorable surface conditions for

148 electrically active microbes [56]. Cathodes were constructed from stainless steel mesh (Type

149304,50 x 50 mesh size; McMaster-Carr, Elmhurst, IL, USA) with a Pt catalyst layer [0.5 mg/cm ${ }^{2}$

150 platinum, (10\% w/w); carbon black, Vulcan XC-72, Fuel Cell Store College Station, TX, USA;

151 and a Nafion binder ( $5 \%$ w/w), $33.33 \mu \mathrm{L} / \mathrm{cm}^{2}$; Sigma Aldrich, St. Louis, MO, USA] painted onto

152 the liquid facing side of the cathode [57]. A gas collection bag was connected to the headspace of

153 the cube MECs with rubber tubing and needles used to connect the bag to the headspace. Cube

154 MECs were run in duplicate.

\section{$155 \quad 2.3 \quad$ Anode Pre-acclimation}

156 Mini MECs were operated with either domestic wastewater (M-WW) or acetate media (M-AC)

157 as substrate for $\sim 2$ months to enrich the anodic biofilm prior to tests with fermentation effluent.

158 Effluent from an MFC reactor was used to inoculate the M-AC reactors to provide an adequate

159 microbial seed, with effluent added in a 1:1 ratio with the acetate medium and was omitted once

160 current production reached at least $0.5 \mathrm{~mA}$. Inoculum addition was not necessary for the M-WW

161 reactors. After the acclimation period in which the reactors produced stable, repeatable current 
162 over multiple cycles, the substrate fed to the M-WW and M-AC reactors was switched from

163 domestic wastewater or acetate to the fermentation effluent sample. This anodic biofilm pre-

164 acclimation procedure was compared to mini MECs that were only fed fermentation effluent

165 with domestic wastewater inoculum, and therefore they did not have a pre-developed anodic

166 biofilm prior to acclimation with the fermentation effluent (M-FE). Domestic wastewater

167 inoculum was added to the M-FE reactors in a 1:1 ratio of fermentation effluent to wastewater,

168 with the wastewater omitted once current production reached at least $0.5 \mathrm{~mA}$.

169 Carbon fiber brush anodes used in cube MECs were acclimated using different procedures. In

170 one set of tests, brush anodes were first pre-acclimated in MFCs using only domestic wastewater

171 as the substrate and inoculum [18]. MFCs used for these tests were 4-cm polycarbonate

172 chambers with the same dimensions as the cube MECs, containing air cathodes made with a Pt

173 catalyst $\left(0.5 \mathrm{mg} / \mathrm{cm}^{2}\right.$ platinum, $10 \% \mathrm{w} / \mathrm{w}$ on carbon black, Vulcan XC-72; Fuel Cell Store)

174 prepared as previously described [58]. A $1000 \Omega$ external load was used as the external resistor

175 during MFC operation, with anodes enriched in MFCs for over one month. Enriched anodes

176 were transferred from MFCs into cube MECs and immediately switched to fermentation effluent

177 (C-WW). The MFC pre-acclimation method was compared to anodes that were started directly in

178 MECs, with a mixture of fermentation effluent and domestic wastewater, without any other

179 anode acclimation (C-FE). Domestic wastewater inoculum was added to C-FE reactors in a 1:1

180 ratio with substrate for the first cycle, with a decreasing inoculum/substrate ratio for the

181 following cycles. Wastewater was omitted once current generation was sustained above $3 \mathrm{~mA}$,

182 which occurred after 3 cycles. 


\subsection{Operation and Measurements}

184 Mini and cube MECs were operated in a $30^{\circ} \mathrm{C}$ controlled temperature room. The anode and 185 cathode of each reactor were connected to a programmable power supply (model 3645A; Circuit 186128 Specialists, Inc.) with an applied potential of $0.7 \mathrm{~V}$ for mini MECs and $0.9 \mathrm{~V}$ for cube MECs

187 [42, 59]. A digital multimeter (Kiethley Instruments, model 2700) recorded voltage

188 measurements for each reactor across a $10 \Omega$ resistor placed in series between the anode and 189 positive terminal on the power supply. Voltage measurements were recorded every 10 minutes 190 on a computer. Ohm's law $(U=I R)$ was used to calculate current, while current density $\left(j ; \mathrm{A} / \mathrm{m}^{2}\right)$

191 was normalized to the projected cathode area and averaged over the time to reach $90 \%$ charge 192 accumulation $\left(I_{\text {avg-90 }}\right)$, as previously described [41]. The total charge recovered over a batch cycle 193 was calculated by integrating the current over the cycle length $\left(C_{T}=\sum I \cdot \Delta t ; \mathrm{C}\right)$. Coulombic 194 efficiency (CE) was based on the total charge measured and change in chemical oxygen demand 195 (COD) over a cycle [41].

196 Substrate was replaced when current decreased below $0.02 \mathrm{~mA}$ in mini MECs and $0.2 \mathrm{~mA}$ in 197 cube MECs [42, 60]. The current density thresholds for substrate replacement were based on 198 previous studies and differ between reactors because of electrode sizes. Gas volume and 199 composition in the cube MECs was determined using a gasbag method based on initial nitrogen 200 gas concentrations [61]. Hydrogen, methane, and nitrogen gas concentrations were determined 201 using a gas chromatograph (Model 310; SRI Instruments, Torrance, CA, USA) with a 6-foot 202 molecular sieve packed 5A column, and argon as a carrier gas. Carbon dioxide was quantified 203 using a GC with a 6-foot porapak Q column, and helium gas carrier. Reactor headspace and gas 204 bags were sampled with an airtight syringe ( $0.5 \mathrm{~mL}$ Gastight syringe, Hamilton Co., Reno, NV, 205 USA). Between cycles, the headspace in mini MECs was sparged with 80:20 $\mathrm{N}_{2} / \mathrm{CO}_{2}$ anaerobic 
gas mixture for 2 minutes and cube MEC headspace was sparged with ultra-high purity $\mathrm{N}_{2}$ gas

207 for 20 minutes. Cube MEC gas bags were sparged by filling with ultra-high purity $\mathrm{N}_{2}$ gas and

208 vacuuming empty three times in succession.

209 Protein concentrations were determined using a bicinchoninic acid assay (Pierce BCA,

210 Thermo Scientific, Rockford, IL, USA) with standard test-tube procedure. Bovine serum

211 albumin (BSA) was used as a protein standard, and samples were incubated at room temperature

212 for 2 hours. Absorbance at $562 \mathrm{~nm}$ was measured using a UV spectrophotometer (DR2700, Hach

213 Co., Loveland, CO, USA) and compared to BSA standards to determine concentration. Chemical

214 oxygen demand (COD) was measured using a standard chromic acid colorimetric method (High

215 range COD vials, Hach Co.).

\section{3. Results and Discussion}

\section{$2173.1 \quad$ Effect of Reactor Type and Acclimation Method on Treatment Performance}

218 At least 79\% of the COD was removed in all MECs, with slight differences between reactor 219 types and pre-acclimation methods. Pre-acclimated mini MECs (M-WW and M-AC) produced 220 slightly lower effluent COD (ANOVA, $\mathrm{p}<0.01)$ than reactors that were not pre-acclimated (M-

221 FE) (Figure 1). The M-WW reactors produced the lowest effluent COD concentration (142 \pm 19

$222 \mathrm{mg} / \mathrm{L})$, followed by M-AC $(175 \pm 25 \mathrm{mg} / \mathrm{L})$, and M-FE (209 $\pm 47 \mathrm{mg} / \mathrm{L})$. For the cube MECs, 223 wastewater acclimated anodes (C-WW) had an average effluent COD concentration of $228 \pm 58$

$224 \mathrm{mg} / \mathrm{L}$ (82\% removal), which was lower but not significantly different (T-test, $\mathrm{p}=0.18$ ) than the 225 average effluent COD measured in the C-FE reactors ( $262 \pm 62 \mathrm{mg} / \mathrm{L}, 79 \%$ removal). COD 226 removals obtained using mini MECs (81-86\%) were about 2-4\% larger on average than cube 227 MECs $(79-82 \%)$ for similar acclimation conditions (T-test, $\mathrm{p}<0.05)$. These COD removals 228 observed in this study compare favorably to the $81-91 \%$ removal efficiency reported by Nam et 
230 efficiency reported by Lalaurette et al. using cube MECs with cellulosic dark fermentation

231 effluent as the substrate [24].

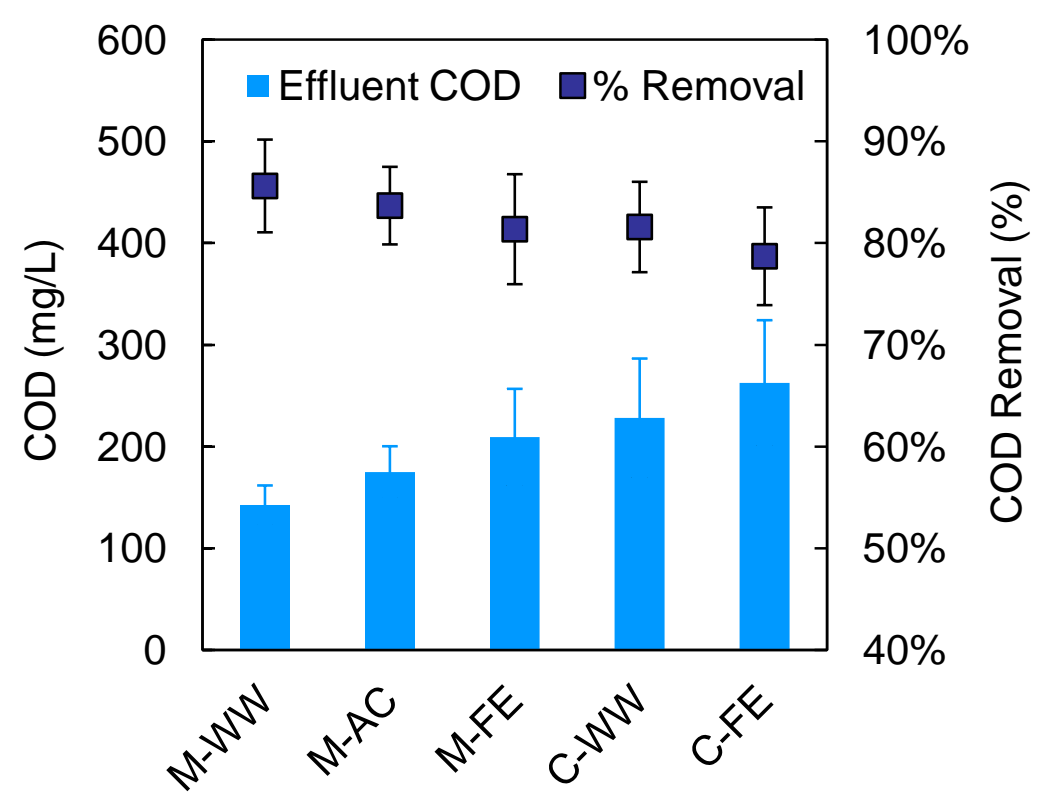

Figure 1. Effluent COD concentrations and total COD removal in mini (M) and cube (C) MECs fed fermentation effluent with different acclimation methods (pre-acclimation to wastewater, WW; pre-acclimation to acetate, AC; or no pre-acclimation using fermentation effluent directly, FE). Influent concentration of diluted fermentation effluent was $1230 \pm 70 \mathrm{mg} / \mathrm{L}$ of COD.

Treatment performance, as measured by the effluent COD concentration, improved over time (22 batch cycles, over $\sim 3$ months) for the mini MECs. Wastewater-acclimated reactors consistently produced lower COD effluent concentration than acetate-acclimated and non-preacclimated reactors throughout the experiment, although effluent COD concentration decreased in all reactors over time and the difference compared to the overall COD removal was relatively small (Figure 2a). Effluent COD concentrations were more variable over time with the cube MECs (18 batch cycles, over 2 months), increasing from cycle 11 to 15 in both C-WW and CFE reactors before decreasing in cycles 16-18 (Figure 2b). C-WW reactors had generally lower effluent COD concentrations than C-FE reactors over the course of the experiment, which was 
246 consistent with the COD removal results observed in mini MECs. Domestic wastewater

247 acclimated reactors showed slightly improved COD effluent quality compared with acetate-

248 acclimated and non-pre-acclimated reactors in both mini and cube MEC tests (T-test, $\mathrm{p}<0.01)$,

249 although the difference in effluent COD concentration was greater between reactor types than

250 acclimation methods. Pre-acclimated reactors (M-WW, M-AC, C-WW) also produced more

251 rapid treatability results since non-pre-acclimated reactors (M-FE, C-FE) required inoculum for 252 the first 3 cycles.

253

254

255

256

257

258

259

260

261

262 conditions.

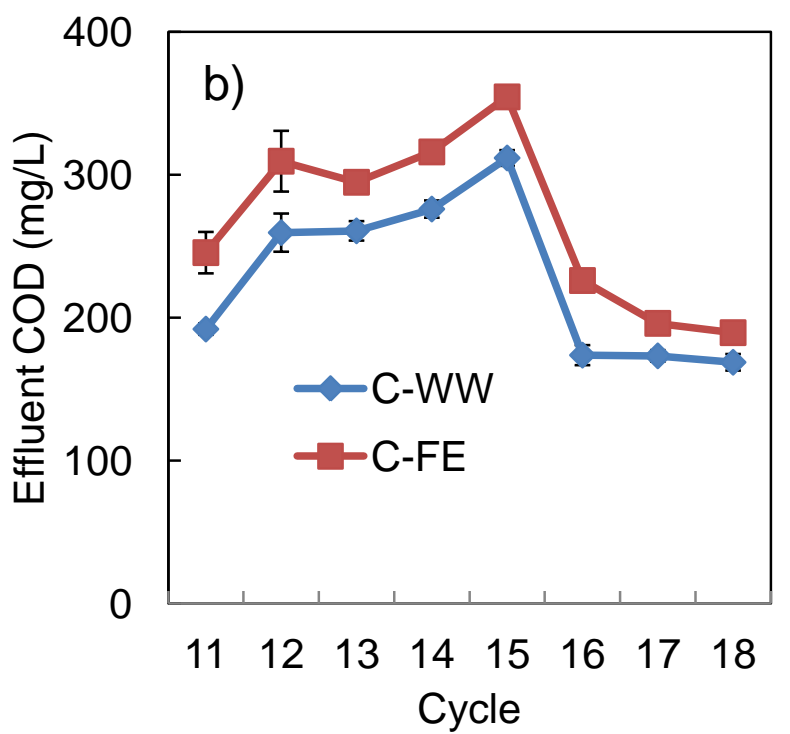

Figure 2. Effluent COD concentrations for differently acclimated (a) mini (M) and (b) cube (C) MECs fed fermentation effluent over multiple cycles.

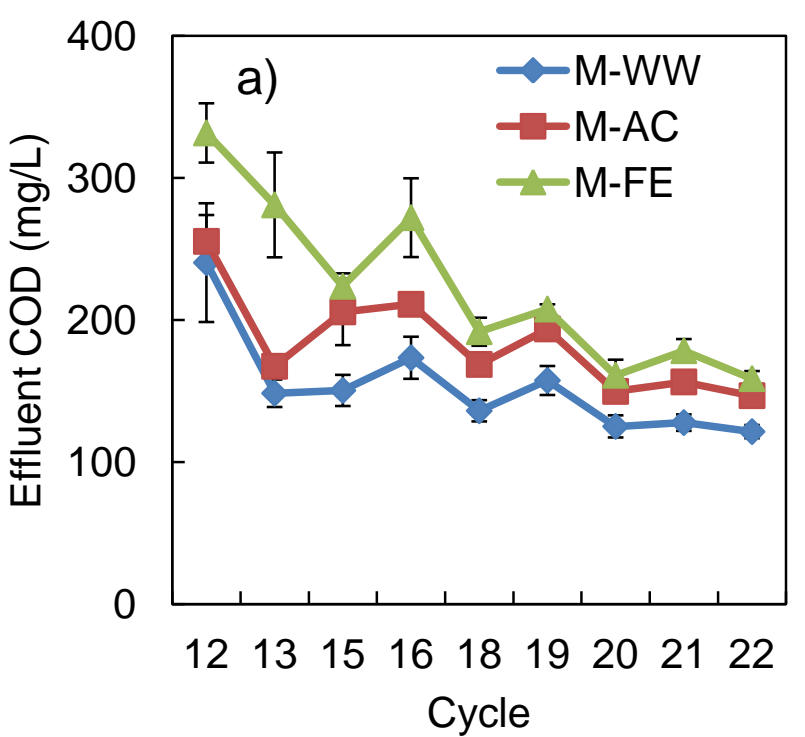


263

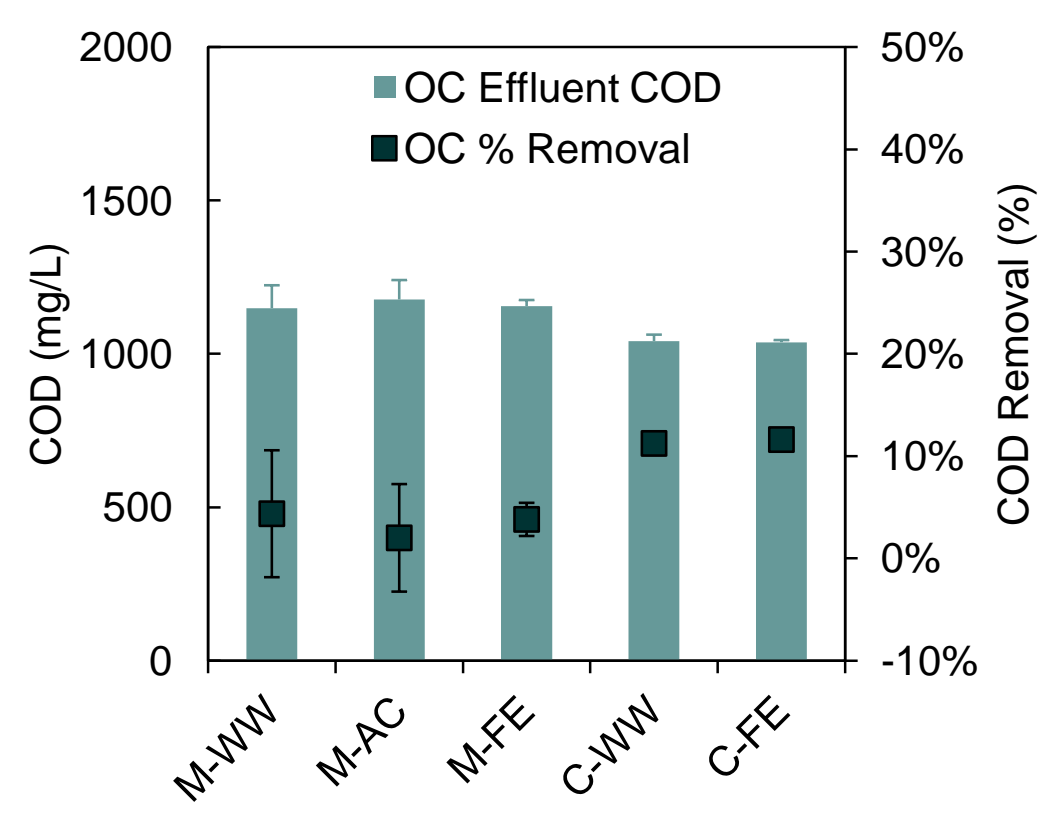

Figure 3. Effluent COD concentration and removal in mini and cube MECs during open circuit (OC) cycle with no current generation.

\subsection{Current Generation and Coulombic Efficiency}

Although COD removal varied among mini MECs based on acclimation method, average current densities in the mini MECs were very similar regardless of acclimation procedures. MWW and M-AC reactors both had average current densities of $I_{\text {avg- } 90}=2.25 \mathrm{~A} / \mathrm{m}^{2}\left(68 \mathrm{~A} / \mathrm{m}^{3}\right)$, while M-FE was slightly lower at $2.20 \mathrm{~A} / \mathrm{m}^{2}\left(66 \mathrm{~A} / \mathrm{m}^{3}\right)$ (Figure 4a). Average current densities in cube MECs were higher than those in the mini reactors, likely because platinum was used as a cathode catalyst in the cube MECs to reduce the electrode overpotential. The average current in the C-WW reactors was $3.77 \pm 0.93 \mathrm{~A} / \mathrm{m}^{2}\left(82 \pm 20 \mathrm{~A} / \mathrm{m}^{3}\right)$, which was not significantly different (T-test, $\mathrm{p}=0.69)$ than current generated in the C-FE reactors $\left(3.89 \pm 0.45 \mathrm{~A} / \mathrm{m}^{2}, 85 \pm 10 \mathrm{~A} / \mathrm{m}^{3}\right)$. Since COD removals varied, but current generation remained nearly constant among the mini MEC reactors with different acclimation methods, the enhanced COD removals of the M-WW reactors was attributed to methanogenesis, and not substrate removal by increased anodic oxidation of organic matter. 
In the mini MECs, coulombic efficiencies (CE) were not significantly different based on 280 acclimation conditions (ANOVA, $\mathrm{p}=0.09$ ), with average CEs of 74-76\% (Figure 4b). CE was

281 significantly higher (T-test, $\mathrm{p}<0.002)$ in the $\mathrm{C}$-FE reactors $(82 \pm 4 \%)$ than the $\mathrm{C}$-WW reactors

$282(76 \pm 4 \%)$. Although this may seem counterintuitive since both $I_{\text {avg-90 }}$ and effluent COD were not

283 significantly different between the C-WW and C-FE reactors, the CE does not reflect the greater

284 variation in those parameters since it is the ratio of removed COD that is measured as current and 285 varies independently.

286

287

288

289

290

291

292

293

294

295
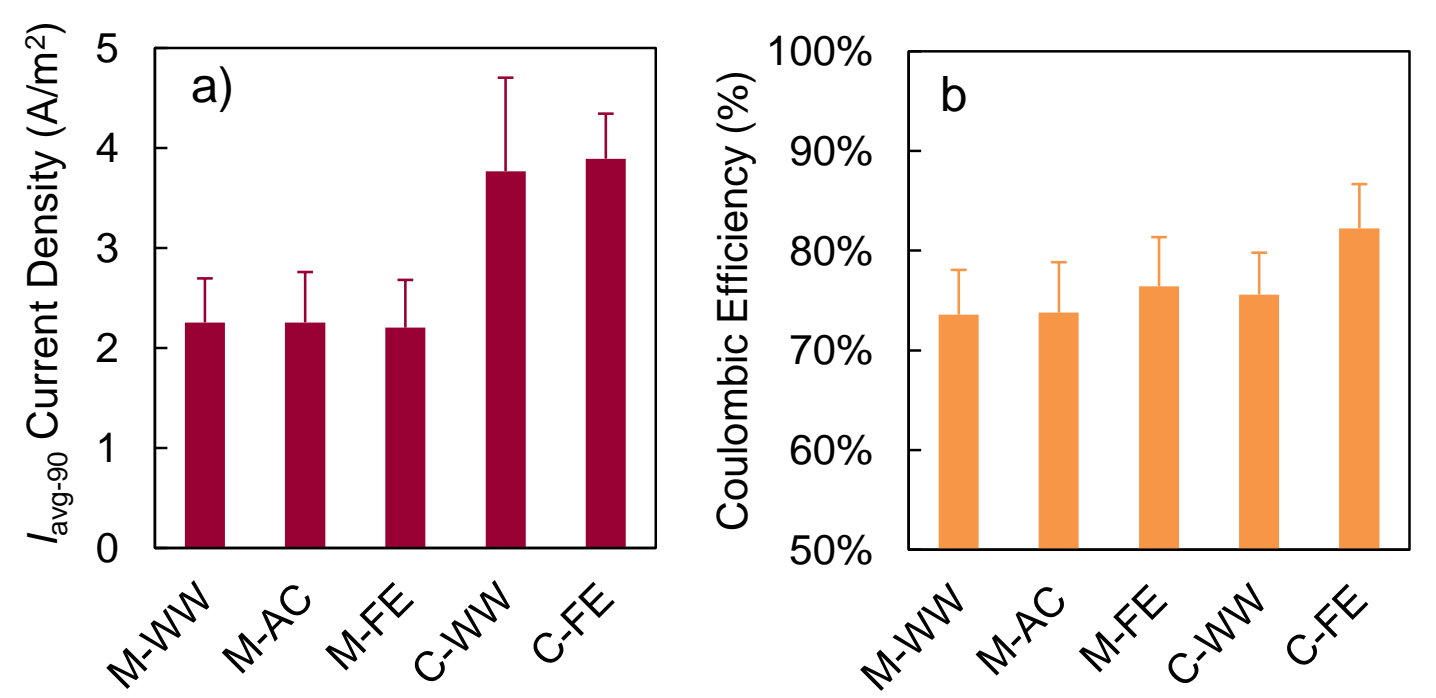

Figure 4. (a) Average current density over the time to $90 \%$ charge accumulation $\left(I_{\text {avg-90 }}\right)$ and (b) coulombic efficiency of mini and cube reactors with different acclimation methods fed fermentation effluent.

\subsection{Gas Recovery and Conversion Efficiency in Cube MECs}

Biogas recovered from the cube MECs primarily consisted of hydrogen. Slightly more total gas was recovered in the $\mathrm{C}-\mathrm{WW}$ reactors $(19.1 \pm 2.8 \mathrm{~mL})$ than the $\mathrm{C}-\mathrm{FE}$ reactors $(17.3 \pm 4.7 \mathrm{~mL})$, but the difference was not significant due to variations in gas recovery among batch cycles and replicates (Figure 5a). Gas composition was also not significantly different between the acclimation methods. Recovered gas was approximately $30 \%$ methane and $60 \%$ hydrogen in both the C-WW and C-FE reactors. 
The hydrogen yields were $352 \pm 72 \mathrm{~mL} \mathrm{H}_{2} / \mathrm{g}$ COD for the C-WW reactors and $334 \pm 120 \mathrm{~mL}$

$298 \mathrm{H}_{2} / \mathrm{g}$ COD for the C-FE reactors (Figure 5b), which were lower than those previously reported

299 for cellulose fermentation effluent $[24,36]$. These lower yields were a result of higher rates of

300 methanogenesis, with methane yields of $185 \pm 21 \mathrm{~mL} \mathrm{CH}_{4} / \mathrm{g} \mathrm{COD}$ in the $\mathrm{C}-\mathrm{WW}$ reactors and

$301164 \pm 21 \mathrm{~mL} \mathrm{CH}_{4} / \mathrm{g} \mathrm{COD}$ in the C-FE reactors. Hydrogenotrophic methanogenesis is difficult to

302 suppress in single chamber systems without the use of chemical inhibitors and hydrogen

303 transport from the dissolved to gas phase can be slower than methanogenic reactions [52, 53, 62].

304 It is possible that the acclimation methods used in this study, which utilized DWW as inoculum

305 and substrate in C-WW reactors and inoculum in C-FE reactors, were less effective at selecting

306 against methanogenic microbes than acetate acclimation, which was used in the previous studies.

307 Various techniques can be used to limit or inhibit methane production, such as adding inhibitors

308 or using two-chamber systems [53, 54], but these were not examined here as the primary focus

309 was on treatment efficiency based on COD and protein removal.

310 Cube MECs were switched to open circuit operation at the end of the experiment to measure

311 background gas production in the absence of current generation. There was relatively little gas

312 measured after open circuit cycles, and it consisted primarily of methane, with slightly more

313 recovered from the $\mathrm{C}$-FE reactors $\left(3.0 \pm 0.3 \mathrm{~mL} \mathrm{CH}_{4}\right)$ than the $\mathrm{C}-\mathrm{WW}$ reactors $(2.5 \pm 0.2 \mathrm{~mL}$

$\left.314 \mathrm{CH}_{4}\right)($ Figure $5 \mathrm{c})$. The presence of methane during open circuit operation indicates that some

315 acetoclastic methanogenesis could have occurred during closed circuit cycles, but the extent to

316 which it contributed to methane recovered during closed circuit cycles, when hydrogen was

317 produced, is not known. It is generally thought that anode respiring microbes outcompete

318 acetoclastic methanogens while current is generated [63], but there was no conclusive way to 
319 differentiate between methane generated by acetoclastic or hydrogenotrophic microorganisms in

320 this study.
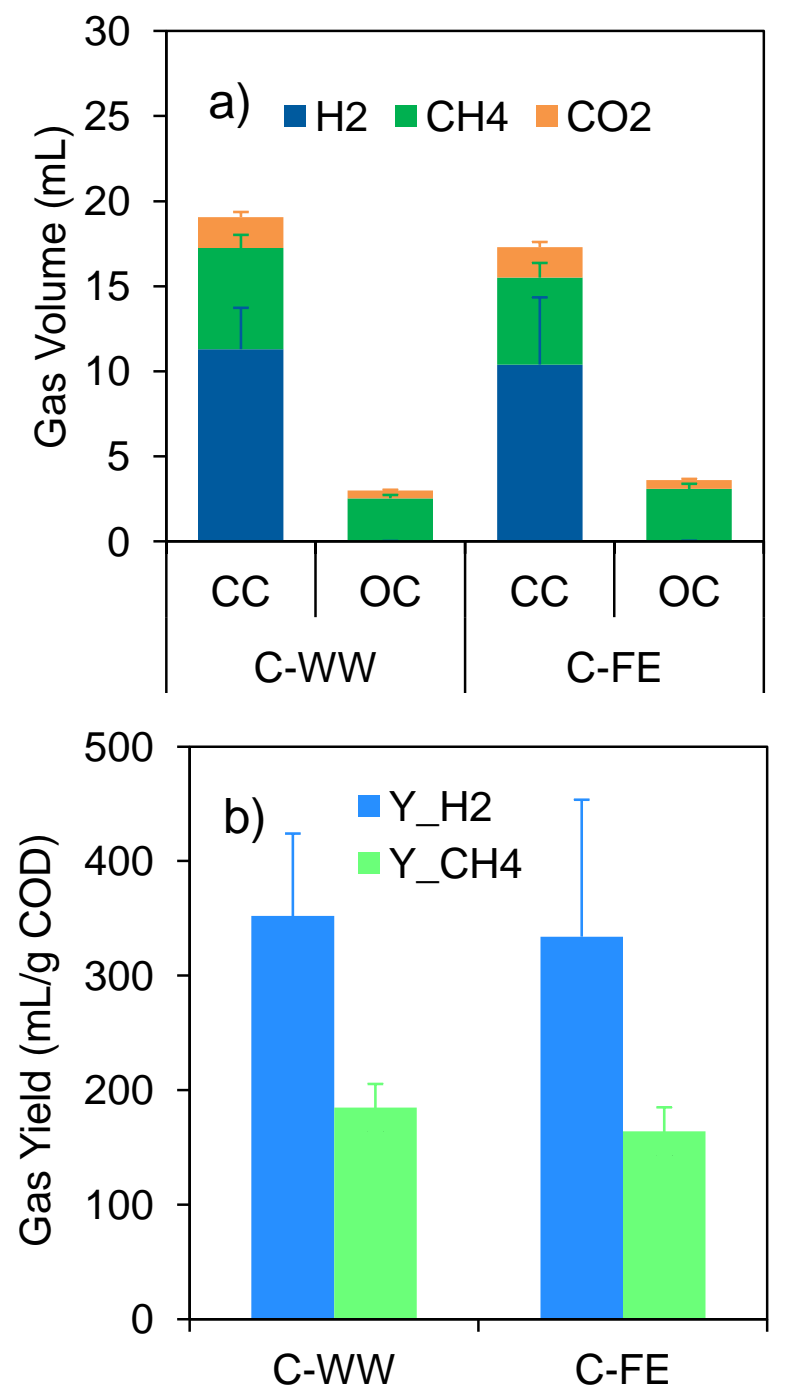

323 Figure 5. (a) Gas recovery in cube MECs fed fermentation effluent with different acclimation 324 procedures during closed circuit (CC) and open circuit (OC) cycles and (b) average hydrogen 325 and methane yields. Average cycle time for cube MECs was $3.0 \pm 0.4$ days.

326 Cathodic gas recovery $\left(r_{\mathrm{H} 2+\mathrm{CH} 4 \text {, cat }}\right)$, which is the fraction of Coulombs measured as current

327 that were recovered in biogas, was significantly ( $T$-test, $\mathrm{p}<0.01)$ lower for the C-FE reactors $(79$

$328 \pm 12 \%)$ than the C-WW reactors $(96 \pm 10 \%)$ (Figure 6 a). Overall recovery $\left(r_{\mathrm{H} 2+\mathrm{CH} 4, \mathrm{COD}}\right)$, which

329 is the ratio of electrons recovered as gas to those removed as COD, was also lower for the C-FE 
330 reactors $(65 \pm 11 \%)$ than the $\mathrm{C}-\mathrm{WW}$ reactors $(72 \pm 7 \%)$. Combined recoveries were calculated 331 assuming that recovered methane was produced via hydrogenotrophic methanogenesis, which 332 requires 4 moles of hydrogen per mol of methane. Cathodic gas recovery was less than $100 \%$ in 333 both C-WW and C-FE reactors, indicating that most of the methane generated in closed circuit 334 cycles was likely generated by hydrogenotrophic methanogens. Methane from acetoclastic 335 microbes would have contributed to gas recovery without generating current. The lower $336 r_{\mathrm{CH} 4+\mathrm{H} 2 \text {,cat }}$ in the C-FE reactors could be the result of side reactions, such as hydrogen cycling, but 337 it is not clear what specifically caused it to be lower than C-WW reactors. Cathodic and overall 338 gas recoveries based only on hydrogen $\left(r_{\mathrm{H} 2, \mathrm{cat}}, r_{\mathrm{H} 2, \mathrm{COD}}\right)$ were not significantly different (Figure $3396 b)$. 
340
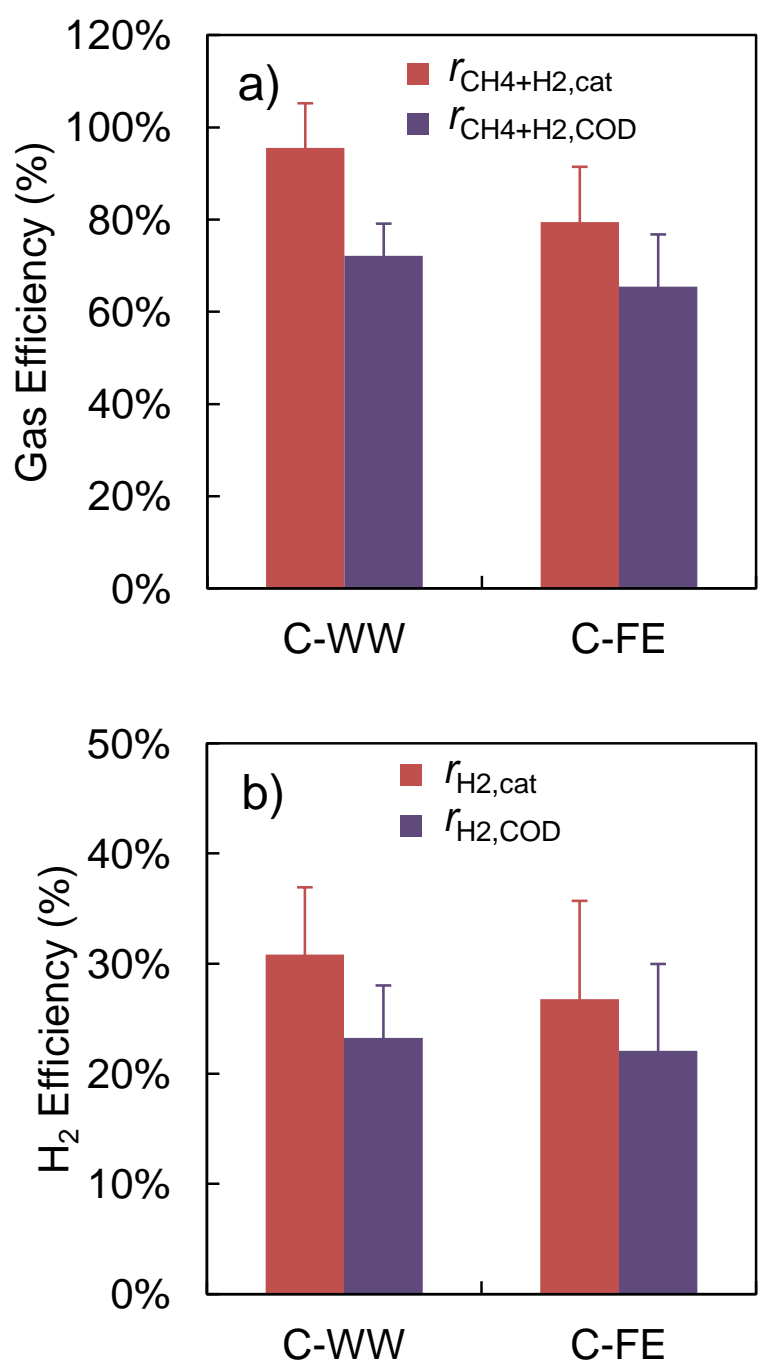

342 Figure 6. (a) Cathodic $\left(r_{\mathrm{H} 2+\mathrm{CH} 4 \text {, cat }}\right)$ and overall $\left(r_{\mathrm{H} 2+\mathrm{CH} 4, \mathrm{COD}}\right)$ recovery of hydrogen and methane 343 and (b) cathodic $\left(r_{\mathrm{H} 2, \text { cat }}\right)$ and overall $\left(r_{\mathrm{H} 2, \mathrm{COD}}\right)$ recovery of hydrogen based on COD and current 344 for cube MECs with different acclimation procedures.

\section{$345 \quad 3.4 \quad$ Protein Removal}

346 Protein removal was examined and compared with COD removal to determine if differences

347 in organic removal between the acclimation methods were the result of changes in protein

348 utilization. Measured protein removal was highest in the pre-acclimated mini MECs, with $84 \pm$

$3492 \%$ of protein removed in the M-WW reactors, followed by the M-AC reactors with $82 \pm 2 \%$ and

350 the M-FE reactors with $79 \pm 2 \%$ (Figure $7 \mathrm{a}$ ). This is consistent with the COD results and 
351 suggests that at least some of the increased COD removal observed for the pre-acclimated

352 reactors (M-WW, M-AC) could be attributed to increased protein utilization in the mini MECs.

353 This difference was not observed in the cube MECs, with 66\% protein removal in both the C-

354 WW and C-FE reactors. Although organic removal was also higher in the cube MECs, the

355 difference between the mini and cube MEC protein removal rates is greater than would be

356 expected based on the COD removal results.

357 To determine the protein fraction of the total influent and effluent COD, the protein

358 concentrations measured with the BCA test were converted into COD concentrations. The COD

359 of the BSA protein standard was measured as $1.62 \mathrm{~g} \mathrm{COD} / \mathrm{g}$ BSA. Using this conversion factor,

360 the estimated COD of the protein in the cube MEC effluent was higher than the measured

361 effluent COD (Figure 7b). The reasons for this are not clear. Absorbance characteristics can vary

362 between different proteins in the BCA assay [64], and since the actual protein composition of the

363 fermentation effluent was not known, the BSA standard may not have been representative of the

364 protein in the fermentation effluent. The color change in the BCA test is generated by the

365 complexation of $\mathrm{BCA}$ and $\mathrm{Cu}^{+}$, so other compounds that can reduce $\mathrm{Cu}^{2+}$ to $\mathrm{Cu}^{+}$would produce

366 a color change [64]. Since the fermentation effluent is a complex sample, it is possible that

367 interfering compounds contributed to the measured protein concentrations. 


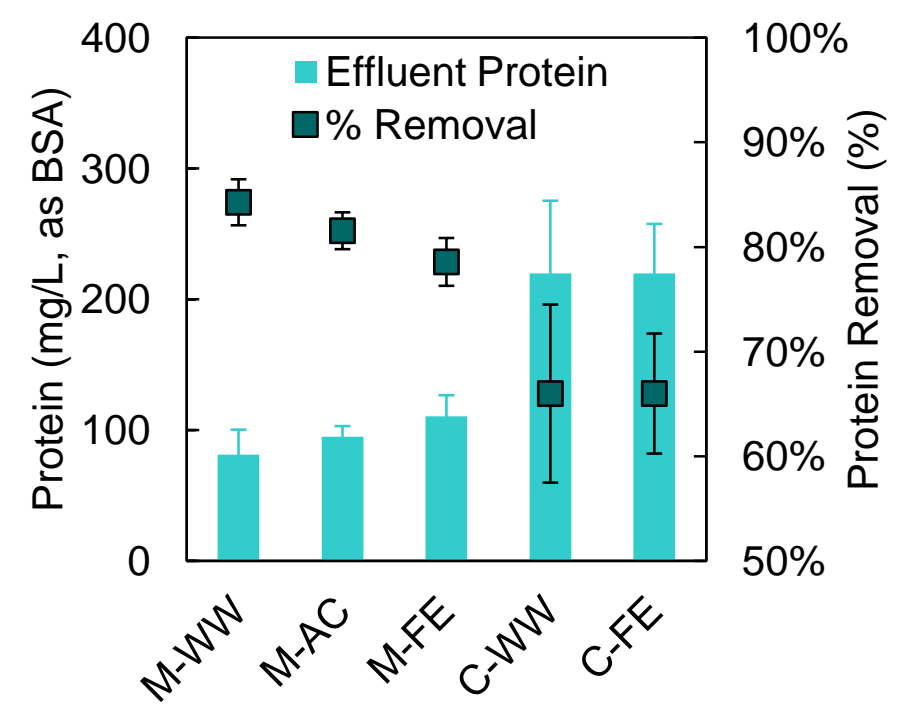

368

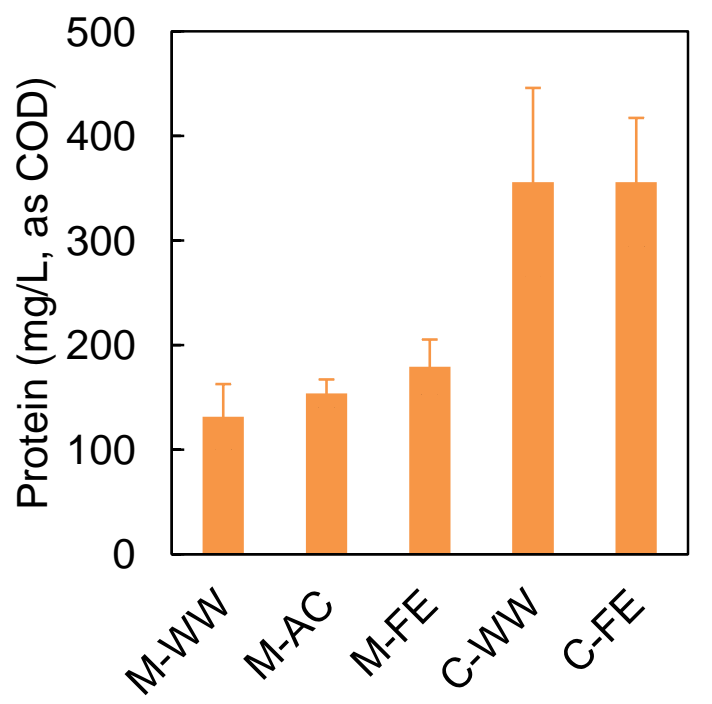
in mini MECs than cube MECs. Acclimating mini MECs to acetate or wastewater prior to tests removal in mini and cube MECs measured using the BCA assay with BSA standard. Average influent protein concentration was $560 \pm 80 \mathrm{mg} / \mathrm{L}$ as BSA. (b) Effluent protein concentrations converted to COD using conversion factor of $1.62 \mathrm{~g} \mathrm{COD} / \mathrm{g}$ BSA.

378 pre-acclimation using domestic wastewater in cube MECs did not have an impact on COD 
treatment. The different acclimation procedures also had no appreciable impact on current

380 generation, and differences in coulombic efficiency were small $(<7 \%)$. Differences in protein

381 removals were also relatively small between acclimation methods in mini MECs (3-5\%), with no

382 differences measured between cube MEC acclimation methods.

383 These results show that acclimating mini MECs to domestic wastewater (i.e. using only

384 domestic wastewater as the inoculum) provided comparable results to tests using fermentation

385 effluent acclimation, based on results of COD removal of fermentation effluent. Pre-acclimation

386 to readily available domestic wastewater is preferred, compared to a specific industrial

387 wastewater, because it allows for more rapid treatability results from the time an industrial

388 wastewater is received to when tests can be conducted using that wastewater. Thus, there is no

389 lag in time for beginning treatability studies with different wastewaters. Domestic wastewater

390 acclimated MECs performed at least as well as acetate acclimated reactors, indicating that

391 acetate addition may not be necessary when developing anodic biofilms for treating wastewaters

392 such as the fermentation effluent tested here. It is often difficult and expensive to ship large

393 volumes of wastewater to a laboratory for treatability testing. The use of mini MECs allows

394 treatability tests to be conducted using small volumes of wastewater, with good replication

395 (triplicate samples were used), and the reactors are relative inexpensive to manufacture. The

396 current densities in mini MECs were slightly lower than those in cube reactors, but COD

397 removals are similar or slightly better than those obtained with cube MECs. It is often difficult to

398 evaluate results in the literature on treatability when different types of MECs are used. We

399 conclude that the simplicity and low cost of the mini MECs could make them a standard for all

400 bioelectrochemical treatment tests, and provide a way to benchmark treatability of different

401 wastewaters based on COD removal and coulombic efficiency. 


\section{Acknowledgments}

404 The authors would like to thank Pin-Ching Maness and Lauren Magnusson at the National

405 Renewable Energy Lab (NREL) for providing fermentation effluent samples. This work was supported by Department of Energy Cooperative Agreement DE-EE0005750 and award KUS-

407 11-003-13 from the King Abdullah University of Science and Technology (KAUST).

\section{References}

410 [1] Angenent LT, Karim K, Al-Dahhan MH, Wrenn BA, Domíguez-Espinosa R. Production of 411 bioenergy and biochemicals from industrial and agricultural wastewater. Trends Biotechnol. $412 \quad 2004 ; 22: 477-85$.

413 [2] Shoener BD, Bradley IM, Cusick RD, Guest JS. Energy positive domestic wastewater 414 treatment: the roles of anaerobic and phototrophic technologies. Environmental Science415 Processes \& Impacts. 2014;16:1204-22.

416 [3] Logan BE. Extracting hydrogen and electricity from renewable resources. Environ Sci 417 Technol. 2004;38:160A-7A.

418 [4] EIA. Impact of increased use of hydrogen on petroleum consumption and carbon dioxide 419 emissions. In: Administration EI, editor. Washington, DC 2008.

420 [5] Rabaey K, Rozendal RA. Microbial electrosynthesis - revisiting the electrical route for 421 microbial production. Nat Rev Microbiol. 2010;8:706-16.

422 [6] Levin DB, Pitt L, Love M. Biohydrogen production: prospects and limitations to practical 423 application. Int J Hydrogen Energy. 2004;29:173-85.

424 [7] Kapdan IK, Kargi F. Bio-hydrogen production from waste materials. Enzyme and Microbial 425 Technology. 2006;38:569-82.

426 [8] Magnusson L, Islam R, Sparling R, Levin D, Cicek N. Direct hydrogen production from 427 cellulosic waste materials with a single-step dark fermentation process. Int J Hydrogen Energy. $428 \quad 2008 ; 33: 5398-403$.

429 [9] Datar R, Huang J, Maness P-C, Mohagheghi A, Czernik S, Chornet E. Hydrogen production 430 from the fermentation of corn stover biomass pretreated with a steam-explosion process. Int $\mathrm{J}$ 431 Hydrogen Energy. 2007;32:932-9. 
[10] Chookaew T, Prasertsan P, Ren ZJ. Two-stage conversion of crude glycerol to energy using dark fermentation linked with microbial fuel cell or microbial electrolysis cell. New Biotechnology. 2014;31:179-84.

[11] Levin DB, Islam R, Cicek N, Sparling R. Hydrogen production by Clostridium thermocellum 27405 from cellulosic biomass substrates. Int J Hydrogen Energy. 2006;31:1496503.

[12] Hawkes DL, Hawkes FR, Hussy I, Kyazze G, Dinsdale R. Continuous dark fermentative hydrogen production by mesophilic microflora: Principles and progress. Int J Hydrogen Energy. 2007;32:172-84.

[13] Wang A, Sun D, Cao G, Wang H, Ren N, Wu W-M, Logan BE. Integrated hydrogen production process from cellulose by combining dark fermentation, microbial fuel cells, and a microbial electrolysis cell. Bioresour Technol. 2011;102:4137-43.

[14] Logan BE. Exoelectrogenic bacteria that power microbial fuel cells. Nat Rev Microbiol. 2009;7:375-81.

[15] Bond DR, Holmes DE, Tender LM, Lovley DR. Electrode-reducing microorganisms that harvest energy from marine sediments. Sci. 2002;295:483-5.

[16] Liu H, Grot S, Logan BE. Electrochemically assisted microbial production of hydrogen from acetate. Environ Sci Technol. 2005;39:4317-20.

[17] Rozendal RA, Hamelers HVM, Euverink GJW, Metz SJ, Buisman CJN. Principle and perspectives of hydrogen production through biocatalyzed electrolysis. Int J Hydrogen Energy. 2006;31:1632-40.

[18] Call D, Logan BE. Hydrogen production in a single chamber microbial electrolysis cell lacking a membrane. Environ Sci Technol. 2008;42:3401-6.

[19] Hu H, Fan Y, Liu H. Hydrogen production using single-chamber membrane-free microbial electrolysis cells. Water Res. 2008;42:4172-8.

[20] Tartakovsky B, Manuel MF, Wang H, Guiot SR. High rate membrane-less microbial electrolysis cell for continuous hydrogen production. Int J Hydrogen Energy. 2009;34:672-7.

[21] Rozendal RA, Hamelers HVM, Molenkamp RJ, Buisman CJN. Performance of single chamber biocatalyzed electrolysis with different types of ion exchange membranes. Water Res. 2007;41:1984-94.

[22] Kim Y, Logan BE. Hydrogen production from inexhaustible supplies of fresh and salt water using microbial reverse-electrodialysis electrolysis cells. Proc Natl Acad Sci. 2011;108:1617681 .

[23] Cusick RD, Kim Y, Logan BE. Energy capture from thermolytic solutions in microbial reverse-electrodialysis cells. Sci. 2012;335:1474-7. 
[24] Lalaurette E, Thammannagowda S, Mohagheghi A, Maness P-C, Logan BE. Hydrogen production from cellulose in a two-stage process combining fermentation and electrohydrogenesis. Int J Hydrogen Energy. 2009;34:6201-10.

[25] Lu L, Ren N, Xing D, Logan BE. Hydrogen production with effluent from an ethanol-H2coproducing fermentation reactor using a single-chamber microbial electrolysis cell. Biosens Bioelectron. 2009;24:3055-60.

[26] Li XH, Liang DW, Bai YX, Fan YT, Hou HW. Enhanced H-2 production from corn stalk by integrating dark fermentation and single chamber microbial electrolysis cells with double anode arrangement. Int J Hydrogen Energy. 2014;39:8977-82.

[27] Pant D, Van Bogaert G, Diels L, Vanbroekhoven K. A review of the substrates used in microbial fuel cells (MFCs) for sustainable energy production. Bioresour Technol. 2009;101:1533-43.

[28] Pant D, Singh A, Van Bogaert G, Olsen SI, Nigam PS, Diels L, Vanbroekhoven K. Bioelectrochemical systems (BES) for sustainable energy production and product recovery from organic wastes and industrial wastewaters. RSC Adv. 2012;2:1248-63. Performance of a pilot-scale continuous flow microbial electrolysis cell fed winery wastewater. Appl Microbiol Biotechnol. 2011;89:2053-63. from domestic wastewater in a pilot-scale microbial electrolysis cell. Appl Microbiol Biotechnol. 2012;97:6979-89.

[31] Heidrich ES, Edwards SR, Dolfing J, Cotterill SE, Curtis TP. Performance of a pilot scale microbial electrolysis cell fed on domestic wastewater at ambient temperatures for a 12 month period. Bioresour Technol. 2014;173:87-95.

491 [32] Kiely PD, Rader G, Regan JM, Logan BE. Long-term cathode performance and the 492 microbial communities that develop in microbial fuel cells fed different fermentation 493 endproducts. Bioresour Technol. 2011;102:361-6.

494 [33] Liu WZ, Huang SC, Zhou AJ, Zhou GY, Ren NQ, Wang AJ, Zhuang GQ. Hydrogen 495 generation in microbial electrolysis cell feeding with fermentation liquid of waste activated 496 sludge. Int J Hydrogen Energy. 2012;37:13859-64.

497 [34] Oh SE, Logan BE. Hydrogen and electricity production from a food processing wastewater 498 using fermentation and microbial fuel cell technologies. Water Res. 2005;39:4673-82.

499 [35] Mahmoud M, Parameswaran P, Torres CI, Rittmann BE. Fermentation pre-treatment of 500 landfill leachate for enhanced electron recovery in a microbial electrolysis cell. Bioresour 501 Technol. 2014;151:151-8. 
[36] Nam J-Y, Yates MD, Zaybak Z, Logan BE. Examination of protein degradation in continuous flow, microbial electrolysis cells treating fermentation wastewater. Bioresour

504 Technol. 2014;171:182-6.

505

506

507

508

509
[37] Lamed R, Setter E, Bayer EA. Characterization of a cellulose-binding, cellulase-containing complex in Clostridium thermocellum. JBacteriol.156:828-36.

[38] Lu L, Xing D, Xie T, Ren N, Logan BE. Hydrogen production from proteins via electrohydrogenesis in microbial electrolysis cells. Biosens Bioelectron. 2010;25:2690-5.

[39] Liu Y, Harnisch F, Fricke K, Sietmann R, Schroder U. Improvement of the anodic bioelectrocatalytic activity of mixed culture biofilms by a simple consecutive electrochemical selection procedure. Biosensors \& Bioelectronics. 2008;24:1006-11.

[40] Zhang F, Xia X, Luo Y, Sun D, Call DF, Logan BE. Improving startup performance with carbon mesh anodes in separator electrode assembly microbial fuel cells. Bioresour Technol. 2013;133:74-81.

[41] Ivanov I, Ren LJ, Siegert M, Logan BE. A quantitative method to evaluate microbial electrolysis cell effectiveness for energy recovery and wastewater treatment. Int J Hydrogen Energy. 2013;38:13135-42.

[42] Ren L, Siegert M, Ivanov I, Pisciotta JM, Logan BE. Treatability studies on different refinery wastewater samples using high-throughput microbial electrolysis cells (MECs). Bioresour Technol. 2013;136:322-8.

[43] Caccavo F, Lonergan DJ, Lovley DR, Davis M, Stolz JF, McInerney MJ. Geobacter sulfurreducens Sp-Nov, A hydrogen-oxidizing and acetate-oxidizing dissimilatory metalreducing microorganism. Appl Environ Microb. 1994;60:3752-9.

[44] Call DF, Logan BE. Lactate Oxidation Coupled to Iron or Electrode Reduction by Geobacter sulfurreducens PCA. Appl Environ Microb. 2011;77:8791-4.

[45] Kiely PD, Cusick R, Call DF, Selembo PA, Regan JM, Logan BE. Anode microbial communities produced by changing from microbial fuel cell to microbial electrolysis cell operation using two different wastewaters. Bioresour Technol. 2011;102:388-94.

[46] Lovley DR. Bug juice: harvesting electricity with microorganisms. Nat Rev Microbiol. 2006;4:497-508.

[47] Yates MD, Kiely PD, Call DF, Rismani-Yazdi H, Bibby K, Peccia J, Regan JM, Logan BE. Convergent development of anodic bacterial communities in microbial fuel cells. ISME J. 2012;6:2002-13.

[48] Ishii S, Suzuki S, Norden-Krichmar TM, Wu A, Yamanaka Y, Nealson KH, Bretschger O. Identifying the microbial communities and operational conditions for optimized wastewater treatment in microbial fuel cells. Water Res. 2013;47:7120-30. 
[49] Call DF, Logan BE. A method for high throughput bioelectrochemical research based on small scale microbial electrolysis cells. Biosens Bioelectron. 2011;26:4526-31.

[50] Logan B, Cheng S, Watson V, Estadt G. Graphite fiber brush anodes for increased power production in air-cathode microbial fuel cells. Environ Sci Technol. 2007;41:3341-6.

[51] Nam JY, Tokash JC, Logan BE. Comparison of microbial electrolysis cells operated with added voltage or by setting the anode potential. Int J Hydrogen Energy. 2011;36:10550-6.

[52] Clauwaert P, Verstraete W. Methanogenesis in membraneless microbial electrolysis cells. Appl Microbiol Biotechnol. 2008;82:829-36.

[53] Chae K-J, Choi M-J, Kim K-Y, Kim IS, Ajayi FF, Chang I-S. Selective inhibition of methanogens for the improvement of biohydrogen production in microbial electrolysis cells. Int $\mathbf{J}$ Hydrogen Energy. 2010;35:13379-86.

[54] Parameswaran P, Torres CI, Lee HS, Krajmalnik-Brown R, Rittmann BE. Syntrophic interactions among anode respiring bacteria (ARB) and Non-ARB in a biofilm anode: electron balances. Biotechnol Bioeng. 2009;103:513-23.

[55] Balch WE, Fox GE, Magrum LJ, Woese CR, Wolfe RS. Methanogens: reevaluation of a unique biological group. Microbiol Rev. 1979;43:260-96.

[56] Feng Y, Yang Q, Wang X, Logan BE. Treatment of carbon fiber brush anodes for improving power generation in air-cathode microbial fuel cells. J Power Sources. 2010;195:1841-4.

[57] Nam J-Y, Logan BE. Enhanced hydrogen generation using a saline catholyte in a two chamber microbial electrolysis cell. Int J Hydrogen Energy. 2011;36:15105-10.

[58] Cheng S, Liu H, Logan BE. Power densities using different cathode catalysts (Pt and CoTMPP) and polymer binders (Nafion and PTFE) in single chamber microbial fuel cells. Environ Sci Technol. 2005;40:364-9.

[59] Cusick RD, Kiely PD, Logan BE. A monetary comparison of energy recovered from microbial fuel cells and microbial electrolysis cells fed winery or domestic wastewaters. Int $\mathbf{J}$ Hydrogen Energy. 2010;35:8855-61.

[60] Liu W, Zhou J, Wang A, Cheng S, Logan BE, Yu H, Deng Y, Nostrand JDV, Wu L, He Z. Geochip-based functional gene analysis of anodophilic communities in microbial electrolysis cells under different operational modes. Environ Sci Technol. 2010;44:7729-35.

[61] Ambler JR, Logan BE. Evaluation of stainless steel cathodes and a bicarbonate buffer for hydrogen production in microbial electrolysis cells using a new method for measuring gas production. Int J Hydrogen Energy. 2011;36:160-6.

[62] Lee H-S, Rittmann BE. Characterization of energy losses in an upflow single-chamber microbial electrolysis cell. Int J Hydrogen Energy. 2010;35:920-7. 
572 [63] Lee HS, Torres CI, Parameswaran P, Rittmann BE. Fate of H-2 in an upflow single573 chamber microbial electrolysis cell using a metal-catalyst-free cathode. Environ Sci Technol.

574 2009;43:7971-6.

575 [64] Wiechelman KJ, Braun RD, Fitzpatrick JD. Investigation of the bicinchoninic acid protein 576 assay: identification of the groups responsible for color formation. Anal Biochem. 1988;175:231$577 \quad 7$. 